\title{
Colgajo neurocutáneo safeno y recambio de espaciador de cemento en el manejo de una artroplastia de rodilla infectada con defecto de cobertura cutánea. Reporte de un caso
}

\author{
Tamara Dainotto, Gonzalo Viollaz, Hernán del Sel, Fernando A. Lopreite \\ Equipo de Cadera y Rodilla, Servicio de Ortopedia y Traumatología, Hospital Británico de Buenos Aires, \\ Ciudad Autónoma de Buenos Aires, Argentina
}

\begin{abstract}
RESUMEN
Los defectos de cobertura asociados a una infección de la prótesis son un desafío al cual nos enfrentamos los cirujanos ortopédicos en el posoperatorio de un reemplazo articular. El objetivo de este artículo es comunicar un caso de defecto de cobertura tratado con un colgajo neurocutáneo safeno por una artroplastia de rodilla infectada. Se recambió el espaciador y se cubrió el defecto tegumentario con colgajo neurocutáneo safeno en un mismo tiempo. Conclusiones: El colgajo neurocutáneo safeno proporciona una adecuada cobertura en la cara anterior de la rodilla y permite tratar defectos tegumentarios asociados a una infección de la prótesis.

Palabras clave: Colgajo neurocutáneo safeno anterógrado; defecto de cobertura; necrosis cutánea; artroplastia de rodilla.

Nivel de Evidencia: IV
\end{abstract}

Saphenous Neurocutaneous Flap and Cement Spacer Replacement in the Management of Arthroplasty of an Infected Knee with a Soft Tissue Coverage Defect. Case Report

\section{ABSTRACT}

Soft tissue defects in the setting of periprosthetic joint infection represent serious problems for orthopaedic surgeons following total joint replacement. This report aims is to show our experience using the proximal-based saphenous neurocutaneous flap for the reconstruction of a wound defect in the treatment of a periprosthetic knee infection. A new cement spacer was placed and a neurocutaneous saphenous flap was performed in the same stage. Conclusions: Soft tissue defects around the knee can be effectively solved with the neurocutaneous saphenous flap, which provides an adequate coverage to this joint within the context of infected arthroplasty.

Keywords: Neurocutaneous saphenous flap; soft tissue defects; tissue necrosis; knee arthroplasty.

Level of Evidence: IV

\section{INTRODUCCIÓN}

La infección de la prótesis asociada a un defecto tegumentario es una complicación temida por los cirujanos ortopédicos luego de un reemplazo articular. La cara anterior de la rodilla es un sitio anatómico dificultoso por los escasos tegumentos que la rodean, así como por la profundidad de los vasos principales. ${ }^{1,2}$

Recibido el 23-8-2020. Aceptado luego de la evaluación el 2-4-2021 • Dra. TAMARA DAINOTTO • dainottotamara@ gmail.com

https://orcid.org/0000-0002-6645-9928 Cómo citar este artículo: Dainotto T, Viollaz G, del Sel H, Lopreite FA. Colgajo neurocutáneo safeno y recambio de espaciador de cemento en el manejo de una artroplastia de rodilla infectada con defecto de cobertura cutánea. Reporte de un caso. Rev Asoc Argent Ortop Traumatol 2021;86(4):529-536. https://doi.org/10.15417/issn. 1852-7434.2021.86.4.1194 
El objetivo de este artículo es exponer los resultados clínico-radiológicos de un paciente con necrosis en la cara anterior de la rodilla, tratado con un colgajo neurocutáneo safeno en el contexto de múltiples intervenciones realizadas a partir de un reemplazo articular.

\section{CASO CLÍNICO}

Hombre de 54 años, con hipertensión arterial, obesidad mórbida y exfumador. En otro Centro, había sido sometido a un reemplazo total de rodilla por genu varo artrósico, en diciembre de 2016. Tuvo una infección aguda de la prótesis con una fístula en el tercio distal de la cicatriz quirúrgica (Figura 1A), por lo que requirió una limpieza quirúrgica y conversión a un espaciador, en junio de 2017, sin rescate de germen (Figura 1B y C). A las tres semanas de la operación, en el examen físico, se observó un área de necrosis de $2 \times 3 \mathrm{~cm}$ en la zona de la fístula inicial (Figura 1D).
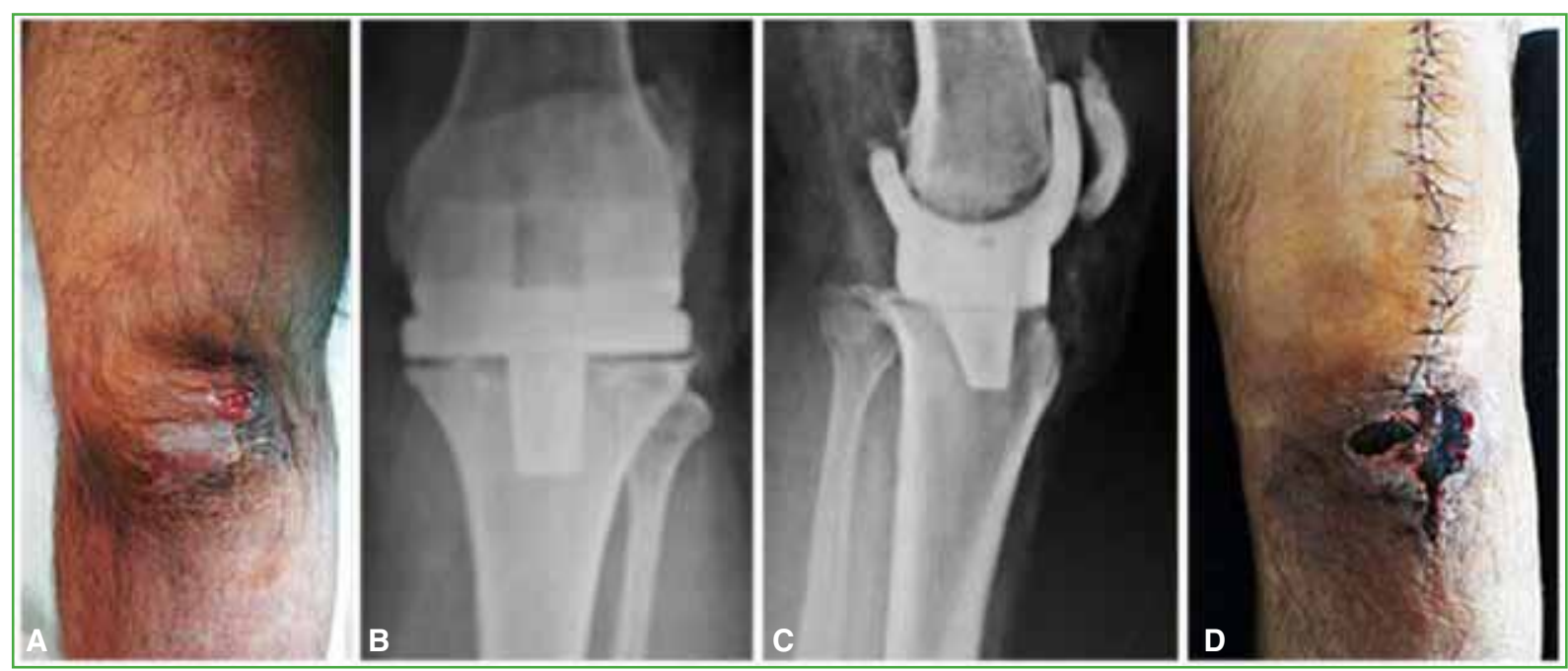

Figura 1. A. Fístula en el tercio distal de la herida quirúrgica en la rodilla izquierda. B y C. Radiografías de frente y de perfil del espaciador de cemento. D. Área necrótica en la zona de la fístula en la cara anterior de la rodilla sobre la inserción del tendón rotuliano en la tuberosidad anterior de la tibia.

El paciente fue derivado a nuestro Servicio. Con el objetivo de curar la infección, entendiendo la importancia de la cobertura vascularizada, se recambió el espaciador (Figura 2) y se trató el defecto de cobertura con el colgajo neurocutáneo safeno descrito por Masquelet, en el mismo tiempo.

\section{Técnica quirúrgica}

Primer tiempo: se ingresó en la rodilla a través de un abordaje pararrotuliano externo respetando la cicatriz inicial, con desbridamiento del tejido necrótico y el tegumento desvitalizado en la porción anteromedial y el tercio distal de la rodilla. Se recambió el espaciador, y se tomaron seis muestras de tejidos profundos de membrana y hueso, y se enviaron para estudio microbiológico. Se procedió a colocar un espaciador de cemento preformado con gentamicina, y el agregado de cemento con $3 \mathrm{~g}$ de vancomicina para complementar los defectos y la cobertura antibiótica local.

Segundo tiempo: manteniendo el decúbito dorsal, con la cadera homolateral en flexión y abducción, y flexión de rodilla a $90^{\circ}$, se diseñó el colgajo neurocutáneo safeno según la marcación cutánea (Figura 3) y la ecografía Doppler previas. Se hizo la incisión exploratoria en el plano subdérmico y se reconoció la vena safena interna como guía. A continuación, se procedió a la disección pedicular $2 \mathrm{~cm}$ hacia anterior, la profundización y, luego, a la incisión de la fascia con reconocimiento por transluscencia del nervio safeno sobre esta. 


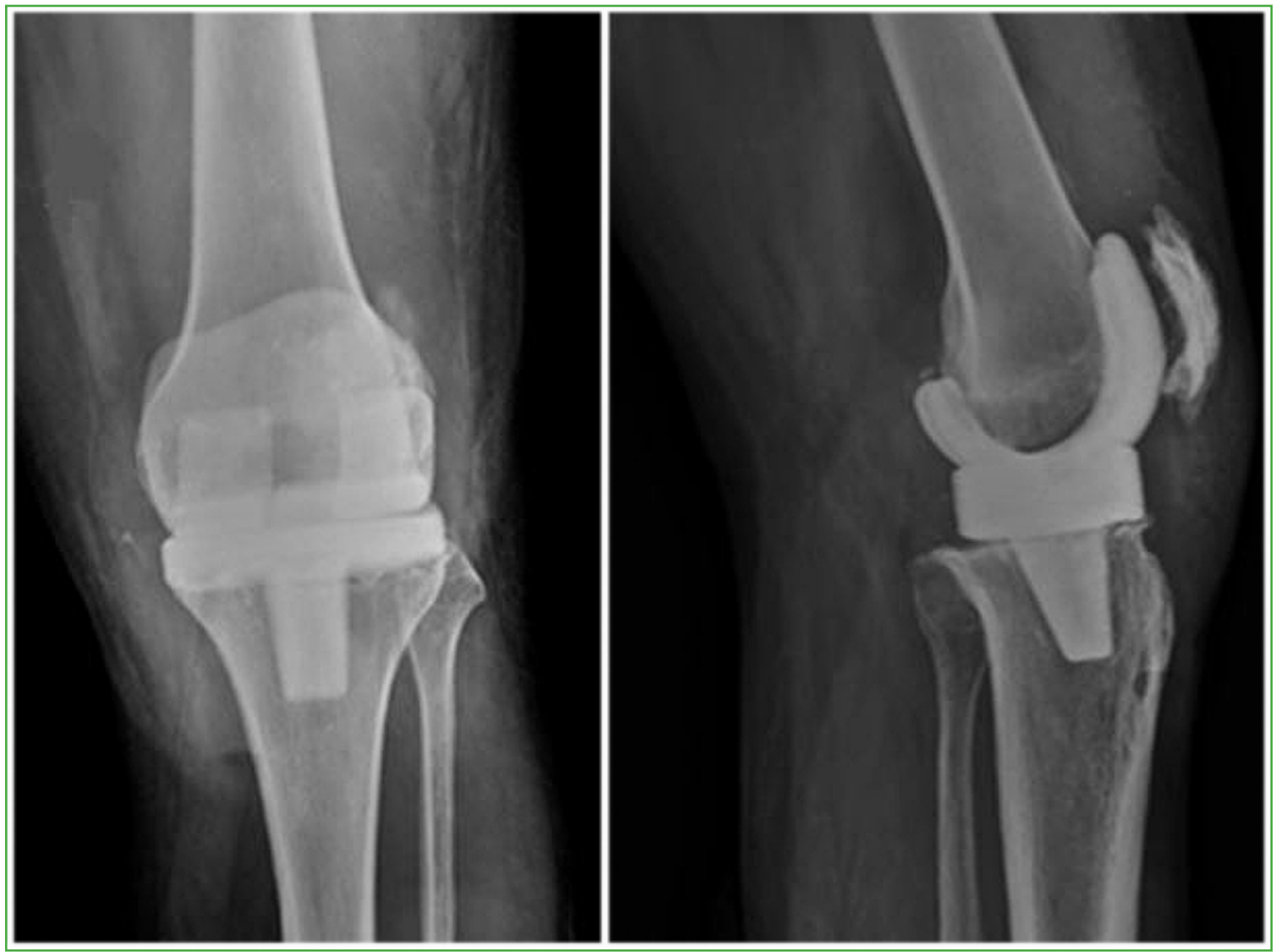

Figura 2. Radiografías de frente y de perfil del nuevo espaciador de cemento con antibiótico. Control posoperatorio.

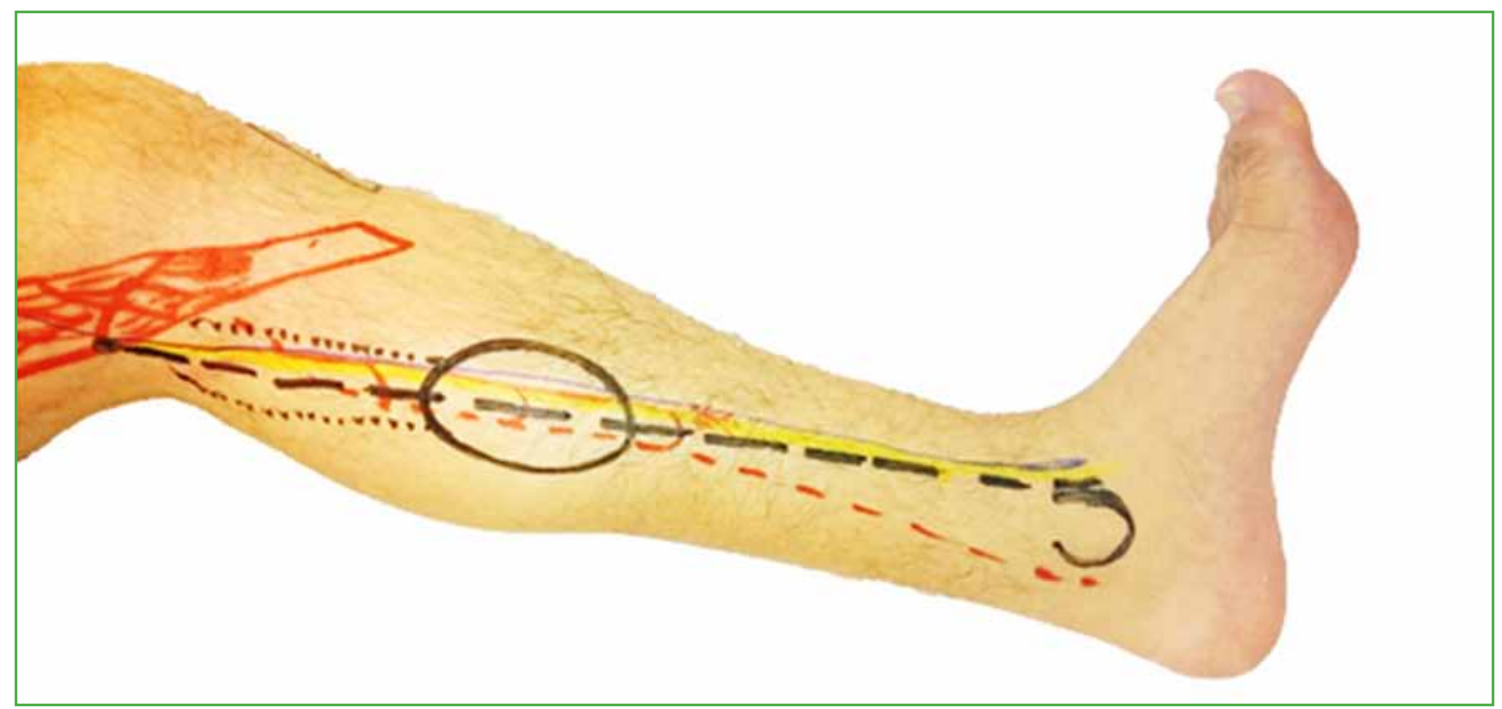

Figura 3. Marcación cutánea preoperatoria de planificación del colgajo de Masquelet. 
La vena safena y el nervio safeno dentro del pedículo aseguran la supervivencia del colgajo. Se procedió al tallado completo del pedículo y el colgajo desde el plano subfascial manteniendo un pedículo de $2 \mathrm{~cm}$ a cada lado de los elementos nobles citados. Se ligaron la vena safena y el nervio safeno en el extremo distal del colgajo. Se lo liberó y se cubrió el defecto (Figura 4).

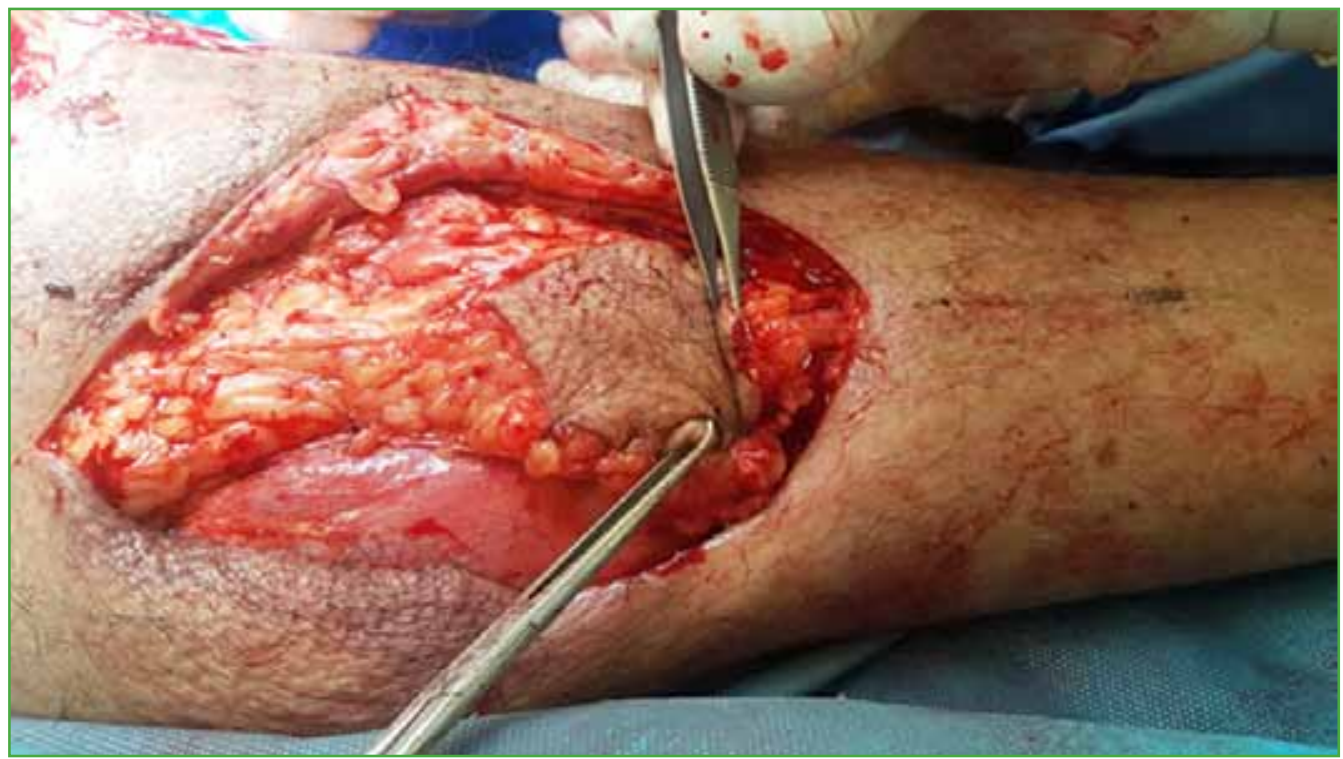

Figura 4. Tallado y liberación del colgajo neurocutáneo safeno.
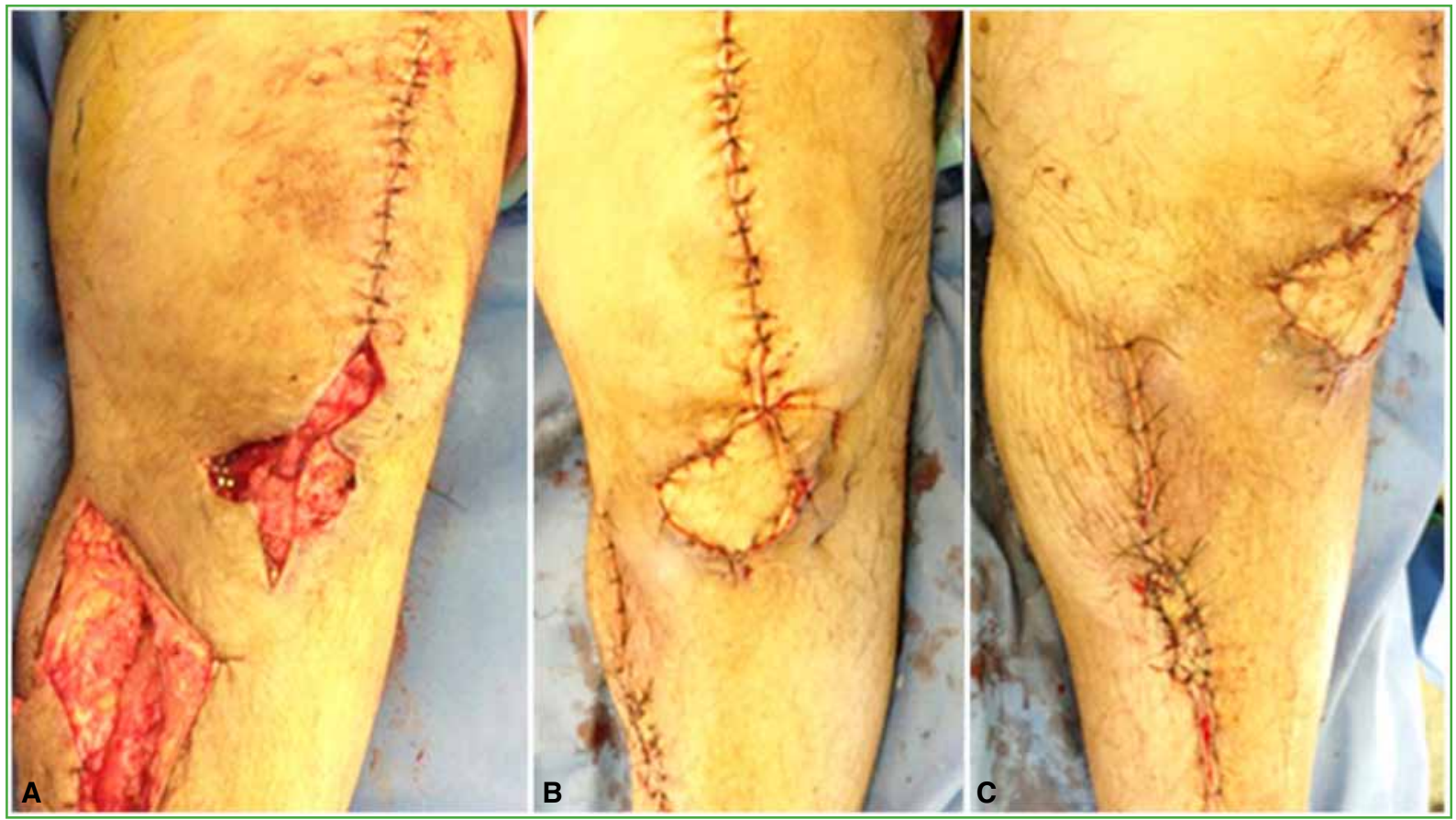

Figura 5. A. Defecto tegumentario en la cara anterior de la rodilla izquierda de 6 x $5 \mathrm{~cm}$. B y C. Cierre de heridas y cobertura del defecto sobre la rodilla, con la colocación de drenaje. 
Se colocaron dos drenajes, se cerraron las heridas y se colocó un vendaje elástico sin compresión (Figura 5). Se controló la vitalidad del colgajo cada 12 h, durante las primeras 72 horas. El paciente realizó la bipedestación con inmovilizador y carga a las $24 \mathrm{~h}$ (Figura 6).

En el cultivo microbiológico, se aisló Klebsiella pneumoniae productora de betalactamasas de espectro extendido. El Servicio de Infectología indicó ertapenem por dos meses.

Con parámetros clínico-humorales de remisión de la infección ${ }^{3}$ y tras haber logrado una cobertura y una cicatrización adecuadas, se realizó la conversión a prótesis de rodilla en enero de 2018 (Figura 7).
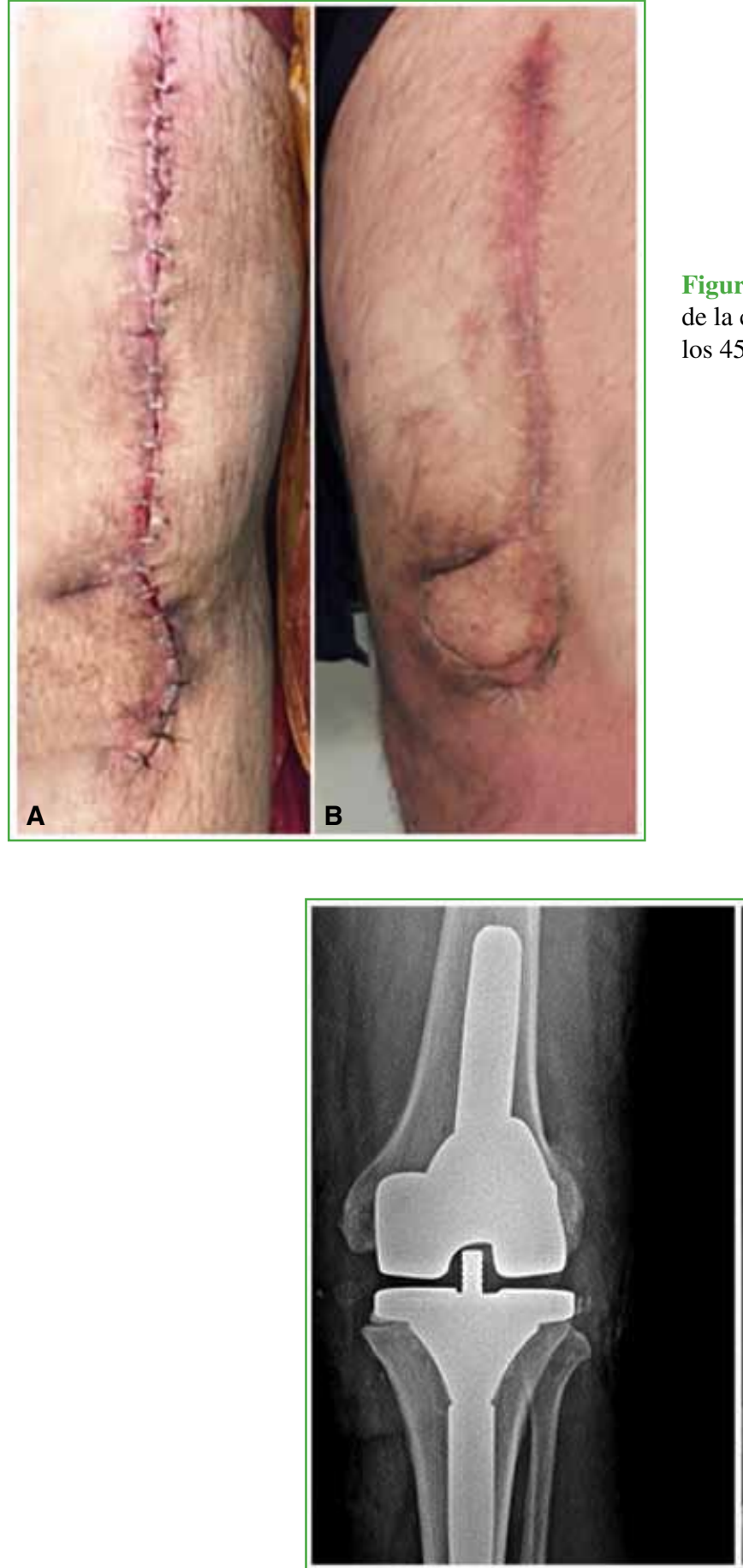

Figura 6. A. Control de la herida a las dos semanas de la cirugía. B. Control de cicatrices quirúrgicas a los 45 días de la operación, ya retirados los puntos.
Figura 7. Radiografías de control de frente $\mathrm{y}$ de perfil en el posoperatorio inmediato.

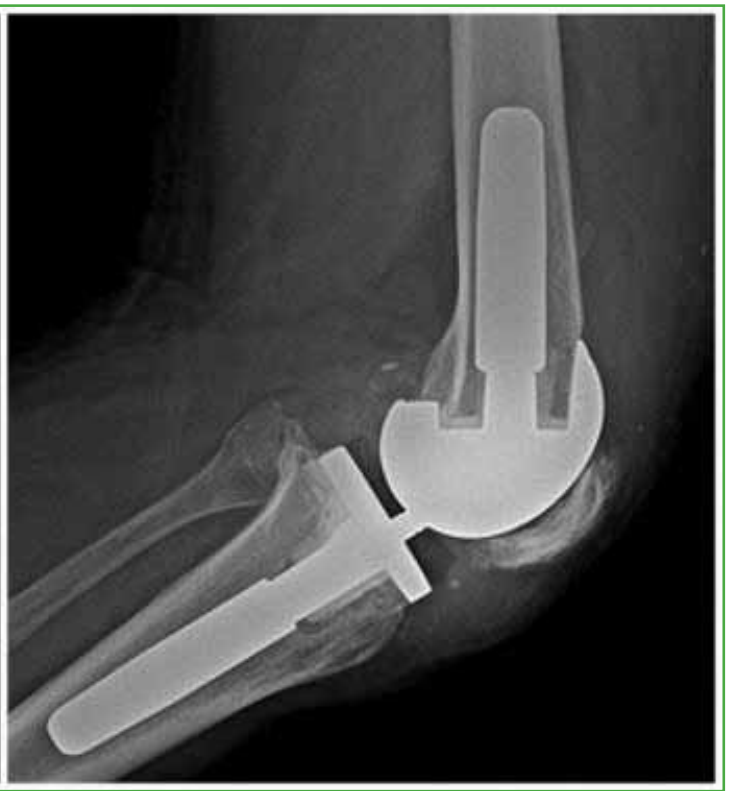


En la actualidad, el paciente no tiene infección según los parámetros clínicos y de laboratorio, camina sin limitación y sin asistencia; no se observan signos radiográficos de aflojamiento de la prótesis (Figura 8) y la flexoextensión es de $0-120^{\circ}$ (Figura 9).

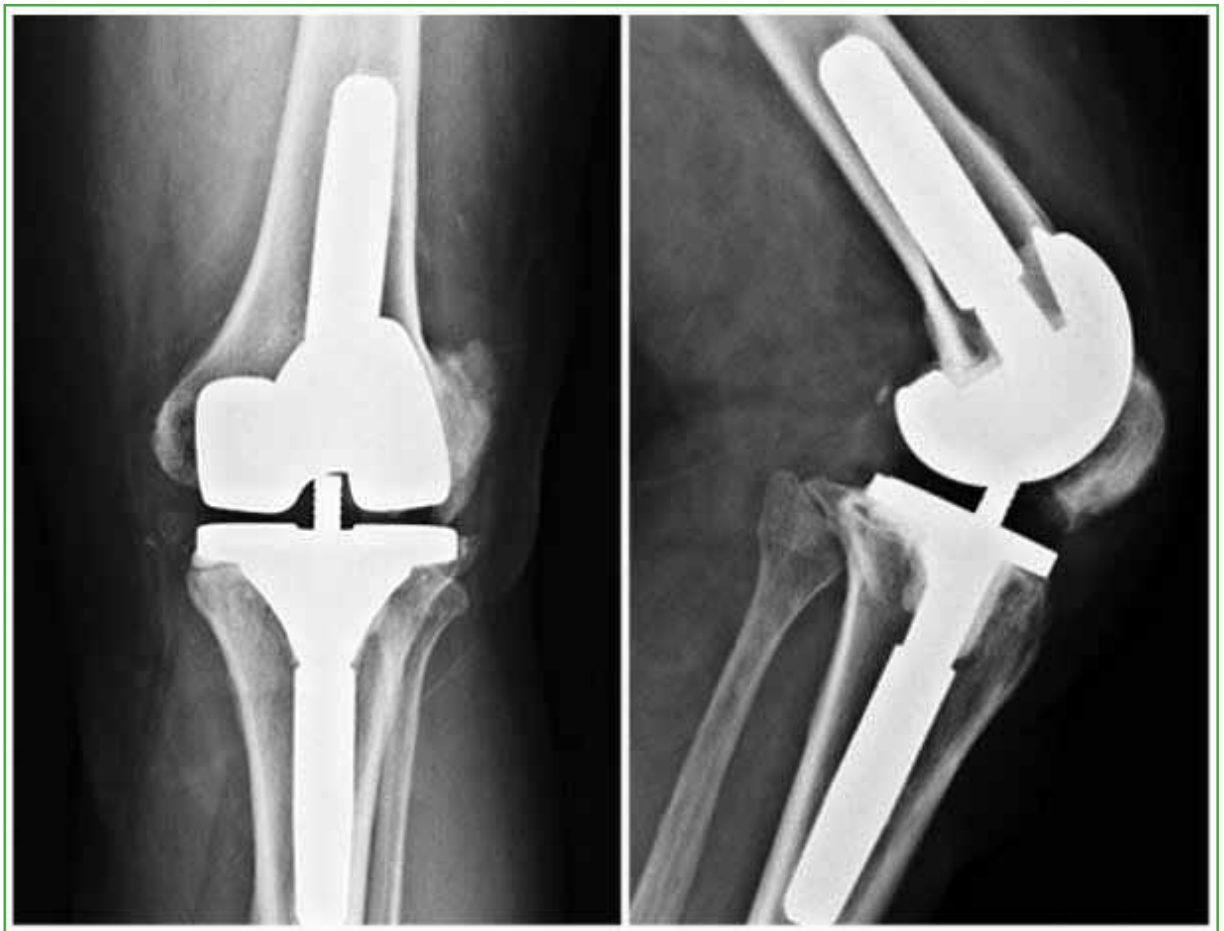

Figura 8. Radiografías de frente y de perfil a los dos años de la conversión de espaciador de cemento a prótesis de revisión de rodilla. No hay signos de aflojamiento u osteólisis.

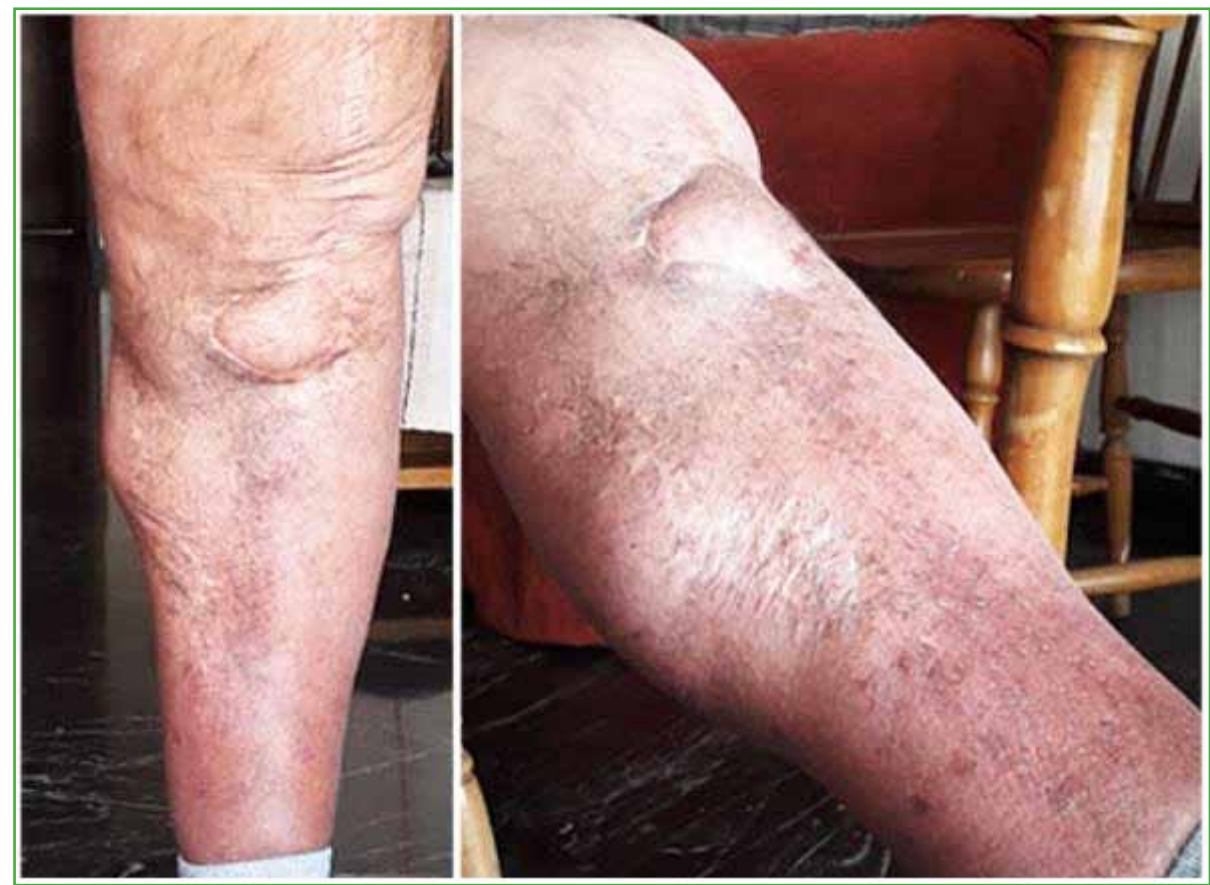

Figura 9. Imágenes actuales de la rodilla en extensión. Control a los dos años y medio de la última cirugía de conversión de espaciador a prótesis. Correcta cicatrización del colgajo y adecuado rango de movilidad. 


\section{DISCUSIÓN}

Las complicaciones en la herida quirúrgica de un reemplazo articular primario o una cirugía de revisión de una prótesis de rodilla pueden llegar a representar un $20 \%$ de todas las complicaciones; existe el riesgo de necrosis cutánea con compromiso de partes blandas, lo que implica un elevado riesgo de infección de la prótesis, defectos de cobertura tegumentaria y hasta la amputación del miembro. ${ }^{1}$ En ocasiones, se requiere el uso de colgajos para lograr un adecuado tratamiento de estos defectos y así planificar una nueva cirugía. ${ }^{2,3}$

La fina piel y los tejidos que rodean a la rodilla permiten los movimientos de flexo-extensión. La cobertura ideal debería tener las mismas características que el tejido perdido con elasticidad, grosor, color, textura y tensión similares. ${ }^{4,5}$

Para planificar el tratamiento de un defecto tegumentario es importante valorar determinados factores, como el tamaño, la localización, la contaminación asociada y el estado de los tejidos circundantes, así como el estado clínico del paciente y sus comorbilidades. ${ }^{3,4}$

Se cuenta con numerosas opciones para tratar defectos de cobertura con exposición ósea o del implante en la cara anterior de la rodilla, entre ellos, los colgajos locales, regionales o a distancia. Los dos primeros brindan la posibilidad de cubrir el defecto con tejidos similares, y la técnica es menos compleja. La principal desventaja es no contar con colgajos de gran tamaño por la escasa zona anatómica dadora, sumado al tejido cicatricial que pudiera existir.

Una opción de colgajo regional históricamente conocido para la porción proximal de la tibia es el del vientre medial del músculo gemelo que proporciona tejido ricamente vascularizado y con un tallado de baja complejidad. ${ }^{6,7}$ La principal desventaja es la dificultad para llegar a cubrir defectos prerrotulianos, aun desinsertando el gemelo de su inserción proximal. También es posible el tallado de colgajos pediculados de la arteria peronea, perforantes de la arteria sural medial o del eje de la arteria circunfleja femoral lateral.

Los colgajos libres permiten cubrir grandes defectos, utilizando dadores de tejidos sanos, y realizar coberturas especializadas. Su uso requiere un entrenamiento microquirúrgico específico.

En 1992, Masquelet detalló, en 64 pacientes, los ejes vasculares que acompañan a tres nervios de la pierna, entre ellos, el nervio safeno. Describió el colgajo neurocutáneo safeno anterógrado para la cobertura de defectos tegumentarios en la rodilla y el tercio proximal de la pierna, aplicándolo en seis casos clínicos. ${ }^{5}$ El nervio safeno emerge de la profundidad del músculo sartorio acompañado por la arteria safena, la cual forma una red anastomótica alrededor del nervio safeno, dando ramas a la piel de la región medial de la pierna desde la rodilla hasta 3-5 $\mathrm{cm}$ proximal al maléolo medial, donde se encuentra la última anastomosis de este eje vascular con la arteria tibial posterior. ${ }^{5,6}$ Existen escasos estudios científicos que describan el uso de este colgajo. Dai y cols. publicaron una serie de 17 pacientes con defectos de cobertura de hasta $9 \times 18 \mathrm{~cm}$ que fueron tratados con colgajos de $11 \times 20 \mathrm{~cm}$, el máximo tamaño reportado hasta la fecha, con un seguimiento promedio de 16 meses. Los autores comunicaron la supervivencia del colgajo en 16 casos y necrosis parcial en un paciente. ${ }^{8}$

A pesar de la escasa bibliografía al respecto, se ha demostrado la utilidad de este colgajo a eje anterógrado para la cobertura de defectos pequeños y medianos en la cara anterior de la rodilla, la tuberosidad anterior de la tibia y el tercio proximal de la pierna, y está contraindicado si hay insuficiencia venosa severa o cicatrices en el área del pedículo.

\section{CONCLUSIONES}

El colgajo neurocutáneo safeno de Masquelet es una alternativa interesante para tratar defectos de cobertura en el contexto de un reemplazo articular de rodilla. Si bien un factor limitante es el tamaño que permite cubrir, genera poca morbilidad al no comprometer estructuras musculares, y se puede optar por el gemelo como segunda opción, si es necesario. En nuestro caso, permitió dar cobertura a un sector anteromedial de la rodilla que se encontraba necrótico, facilitando el tratamiento de la infección de la prótesis de rodilla.

Conflicto de intereses: Los autores no declaran conflictos de intereses. 


\section{BIBLIOGRAFÍA}

1. Ries MD. Skin necrosis after total knee arthroplasty. J Arthroplasty 2002;17(4 Suppl. 1):74-7. https://doi.org/10.1054/arth.2002.32452

2. Panni AS, Vasso M, Cerciello S, Salgarello M. Wound complications in total knee arthroplasty. Which flap is to be used? With or without retention of prosthesis? Knee Surg Sport Traumatol Arthrosc 2011;19(7):1060-8. https://doi.org/10.1007/s00167-010-1328-5

3. Parvizi J, Tan TL, Goswami K, Higuera C, Della Valle C, Chen AF, et al. The 2018 definition of periprosthetic hip and knee infection: an evidence-based and validated criteria. J Arthroplasty 2018;33(5):1309-1314.e2. https://doi.org/10.1016/j.arth.2018.02.078

4. Ravindra Bharathi R, Ramkumar S, Venkatramani H. Soft tissue coverage for defects around the knee joint. Indian J Plast Surg 2019;52(1):125-33. https://doi.org/10.1055/s-0039-1688536

5. Osei DA, Rebehn KA, Boyer MI. Soft-tissue defects after total knee arthroplasty: management and reconstruction. $J$ Am Acad Orthop Surg 2016;24(11):769-79. https://doi.org/10.5435/JAAOS-D-15-00241

6. Rao AJ, Kempton SJ, Erickson BJ, Levine BR, Rao VK. Soft tissue reconstruction and flap coverage for revision total knee arthroplasty. J Arthroplasty 2016;31(7):1529-38. https://doi.org/10.1016/j.arth.2015.12.054

7. Menderes A, Demirdover C, Yilmaz M, Vayvada H, Barutcu A. Reconstruction of soft tissue defects following total knee arthroplasty. Knee 2002;9(3):215-9. https://doi.org/10.1016/s0968-0160(02)00010-8

8. Dai J, Chai Y, Wang C, Wen G. Proximal-based saphenous neurocutaneous flaps: A novel tool for reconstructive surgery in the proximal lower leg and knee. J Reconstr Microsurg 2013;29(6):373-8.

https://doi.org/10.1055/s-0033-1343958 